\title{
Temperature-fastened sodium inactivation accounts for energy efficient cortical action potentials in mammalian brains
}

Yuguo Yu

From Twenty First Annual Computational Neuroscience Meeting: CNS*2012

Decatur, GA, USA. 21-26 July 2012

Recent experimental evidencs showed that action potential (AP) generation in mammalian, versus invertebrate, axons is remarkably energy efficient [1]. Here we per- form both computational (based on both traditional Hodgkin-Huxley model [2] and a cortical axon model [3] whose parameters are modified from experimental

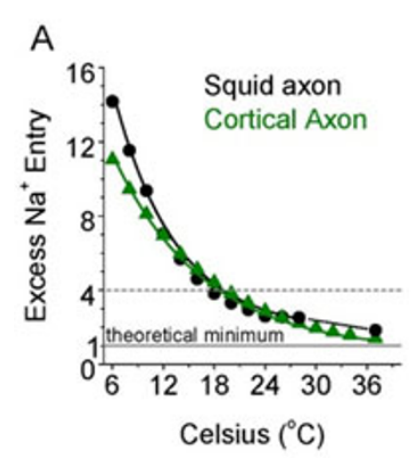

\section{B $\quad \mathrm{T}=18\left({ }^{\circ} \mathrm{C}\right)$}
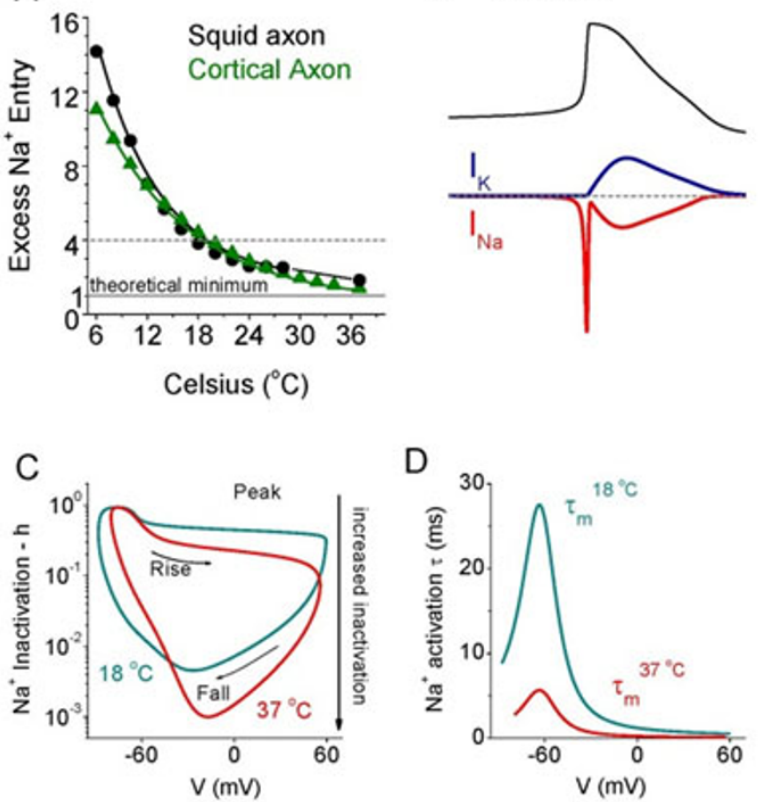

D

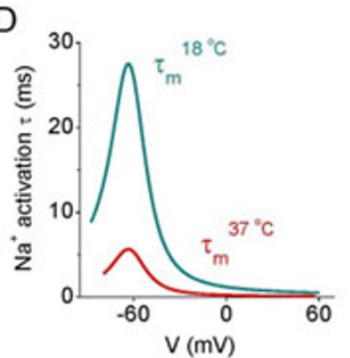

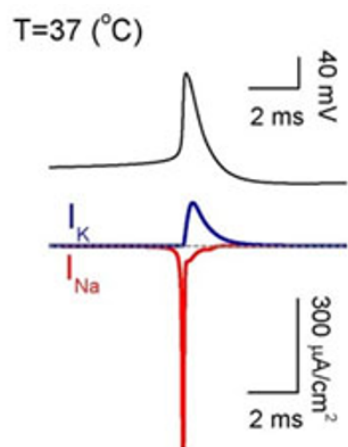

E

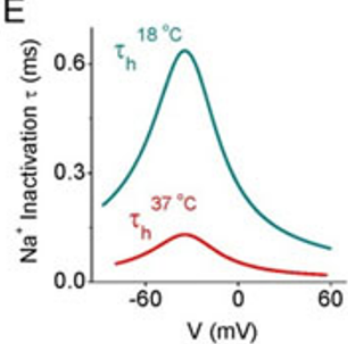

Figure 1 Energy efficiency of AP increases as temperature increases. A. Sodium entry ratio (SER, defined as $\int I_{\mathrm{Na}}(t) d t /\left(C_{m} \Delta V\right)$, where $I_{N a}(t)$ is $N a+$ current, $C_{m}$ is capacitance, $\triangle V$ is the change in voltage during an AP) vs temperature. For both squid axon and cortical axon models, increasing temperature strongly decreases SER during AP. At $18^{\circ} \mathrm{C}$, SER is approximately 4, while at $37^{\circ} \mathrm{C}$, SER reaches 1.89 and 1.41 . B. Cortical AP, INa and $I_{K}$ at 18 and $37^{\circ} \mathrm{C}$, respectively. C. The inactivation level of $\mathrm{Na}^{+}$channel increases as temperature increases, indicating a more closed state for a high temperature, decreasing the leaky $\mathrm{Na}+$ through membrane. D. Decrease of $\mathrm{Na}+$ activation time constant as temperature increases. E. Decrease of $\mathrm{Na}+$ inactivation time constant as temperature increases.

Correspondence: yuyuguo@fudan.edu.cn

Center for Computational Systems Biology, School of Life Sciences, Fudan University, Shanghai, 200433, China 
data) and experimental studies. Each supports that temperature is a major factor which directly modulates the level of energy cost of APs. Temperature increase results in a remarkable decrease in time constant of sodium channel closing and an increase in inactivation level of $\mathrm{Na}+$ channel due to the Q10 effect (which quantifies the temperature dependent rate of biochemical reactions). This results in a marked reduction in overlap of the inward $\mathrm{Na}+$, and outward $\mathrm{K}+$ currents. As a consequence, the $\mathrm{Na}+$ entry ratio gradually reaches to 1 (the theoretical optimal level, which requires only minimal $\mathrm{Na}+$ charge for generating an AP) as temperature rises. Moreover, we also notice a remarkable exponential increase in firing rate and an exponential decrease in spike duration by both experimental and model studies. The total energy charge in response to a signal reaches a global minimum when temperature is around 37-42 ${ }^{\circ} \mathrm{C}$. This suggests that warm body temperatures may help the mammalian brain to operate with minimal energy cost.

In addition, classic investigations by Hodgkin of squid giant axon revealed an excess entry of approximately 4 times as much $\mathrm{Na}^{+}$as minimally required to generate an AP [4]. This value of 4 times excess $\mathrm{Na}^{+}$entry has figured prominently in estimates of the distribution of the sources of energy consumption in the mammalian brain. Here we have to point out that this calculation is based on original Hodgkin-Huxley model with a temperature at $18{ }^{\circ} \mathrm{C}$. It should not be used for calculation of mammalian brain energy budget since mammalian animals have a warm body temperature around $37{ }^{\circ} \mathrm{C}$, around which the sodium entry ratio is close to 1.3 .

Published: 16 July 2012

\section{References}

1. Alle $\mathrm{H}$, Roth $\mathrm{A}$, Geiger JR: Energy-efficient action potentials in hippocampal mossy fibers. Science 2009, 325:1405-1408.

2. Hodgkin AL, Huxley AF: A quantitative description of membrane current and its application to conduction and excitation in nerve. J Physiol 1952, 117:500-44.

3. Yu Y, Shu Y, McCormick DA: Cortical action potential backpropagation explains spike threshold variability and rapid-onset kinetics. J Neurosci 2008, 28(29):7260-7272.

4. Attwell $D$, Laughlin SB: An energy budget for signaling in the grey matter of the brain. J Cereb Blood Flow Metab 2001, 21(10):1133-1145.

doi:10.1186/1471-2202-13-S1-P5

Cite this article as: $\mathrm{Yu}$ : Temperature-fastened sodium inactivation accounts for energy efficient cortical action potentials in mammalian brains. BMC Neuroscience 2012 13(Suppl 1):P5.
Submit your next manuscript to BioMed Central and take full advantage of:

- Convenient online submission

- Thorough peer review

- No space constraints or color figure charges

- Immediate publication on acceptance

- Inclusion in PubMed, CAS, Scopus and Google Scholar

- Research which is freely available for redistribution

Submit your manuscript at www.biomedcentral.com/submit 